\title{
Папиллярная фиброэластома необычной локализации (случай из практики)
}

\author{
Витовский Р. М. ${ }^{1,2}$, Захарова В. П. ${ }^{2}$, Дядюн Д. Н. ${ }^{2}$, Исаенко В. В. ${ }^{1}$, Семенив П. М. ${ }^{2}$ \\ ${ }^{1}$ ГУ «Национальный институт сердечно-сосудистой хирургии имени Н. М. Амосова НАМН» (Киев) \\ 2 Национальная медицинская академия последипломного образования имени П. Л. Шупика (Киев)
}

\begin{abstract}
Папиллярная фиброэластома (фиброэластическая папиллома, папиллома клапанов, фиброма клапанов) доброкачественное внутриполостное образование, исходящее из эндокарда. Папиллярная фиброэластома (ПФ) может поражать любой отдел сердца, но наиболее часто - хордальный аппарат и створки клапанов. В $10 \%$ случаев отмечается множественный характер поражения. В абсолютном большинстве случаев поражаются левые отделы сердца. Макроскопически ПФ представляет собой, как правило, небольшую опухоль диаметром 1,5-2,0 см, белесоватого цвета, мягко- или плотноэластической консистенции, напоминающую сосочковые разрастания эндокарда Lambl's. Диагностика ПФ чрезвычайно трудна, т. к. патогномоничных клинических и лабораторных признаков она не имеет. Применение ЭхоКГ чаще всего обеспечивает точную и своевременную диагностику опухоли.
\end{abstract}

Целью работы явилась демонстрация особенностей локализации, клинического течения и хирургического лечения папиллярной фиброэластомы левого желудочка.

Материалы и методы. По состоянию на 01.01.2018 года в НИССХ имени Н. М. Амосова НАМН проводилось лечение 916 больных с опухолями сердца. Папиллярная фиброэластома была диагностирована в 9 случаях, что составило $1,0 \%$ среди всех первичных опухолей сердца.

Результаты и обсуждение. Мы представляем результаты клинического наблюдения очередного пациента, у которого была выявлена папиллярная фиброэластома, локализовавшаяся на папиллярной мышце митрального клапана. По данным трансторакальной ЭхоКГ, в полости левого желудочка лоцировалось подвижное образование с нечеткими фрагментированными контурами, без капсулы, исходящее из папиллярных мышц, размерами $1,6 \mathrm{x} 0,8$ см. Значительная фрагментированность образования и высокая подвижность визуализируемых фрагментов предполагала высокую угрозу их отрыва с последующими эмболическими осложнениями. В связи с этим было принято решение выполнить операцию, направленную на удаление новообразования, в экстренном порядке.

Выводы. Описанный случай демонстрирует возможность внеклапанной локализации и бессимптомного течения папиллярной фиброэластомы. При этом тактика экстренного и радикального хирургического лечения всегда должна быть соблюдена.

Ключевые слова: опухоли сердиа, папиллярная фиброэластома, трансторакальное ЭхоКГ, хирургическое лечение.

Среди доброкачественных новообразований сердца, помимо наиболее часто встречающихся миксом, выделяют группу немиксоматозных доброкачественных опухолей, к которым относятся рабдомиомы, фибромы, липомы, гемангиомы, тератомы, мезенхимомы, невриномы, хондромы и др. [1-4]. Немиксоматозные доброкачественные новообразования сердца составляют до $3,5 \%$ всех первичных опухолей сердца [1-5]. Одной из немиксоматозных доброкачественных опухолей сердца является довольно редко встречающаяся папиллярная фиброэластома (ПФ), которая может располагаться в любом отделе сердца, однако чаще всего местом прикрепления является непосредственно один из клапанов сердца $[6,7]$.
В публикациях имеются сообщения лишь о единичных наблюдениях этого заболевания - как в клинике, так и при патологоанатомических исследованиях $[8,9]$. Исследования данной патологии представляют интерес для кардиохирургов и кардиологов в клиническом и патогистологическом аспектах, поскольку современные диагностические средства позволяют только ориентировочно определить характер новообразования сердца до выполнения оперативного вмешательства и патогистологического исследования.

Учитывая изложенное, мы сочли целесообразным представить наше очередное наблюдение ПФ сердца, определить особенности клинического течения, инструментальной диагностики, а также хирургического лечения этого заболевания. Кроме того, необычная 
локализация этого новообразования также представляет определенный интерес, что требует изложения в медицинской литературе.

Целью работы явилась демонстрация особенностей локализации, клинического течения и хирургического лечения папиллярной фиброэластомы левого желудочка.

Материалы и методы. По состоянию на 01.01.2018 года в НИССХ имени Н. М. Амосова НАМН проводилось лечение 916 больных с опухолями сердца. В подавляющем большинстве случаев наблюдались доброкачественные опухоли сердца. При этом миксомы выявлены у 815 больных, другие немиксоматозные доброкачественные новообразования отмечены в 35 случаях, злокачественные новообразования выявлены у 66 пациентов.

Папиллярная фиброэластома была диагностирована в 9 случаях, что составило $1,0 \%$ среди всех первичных опухолей сердца. Изучались особенности клинического течения заболевания. Применялись как лабораторные, так и инструментальные методы исследования, среди которых ведущую роль играла эхокардиография, позволяющая выявить новообразование, определить объем поражения сердечных структур, а также степень возможного нарушения гемодинамики.

Результаты. Мы представляем результаты клинического наблюдения очередного пациента, у которого была выявлена папиллярная фиброэластома, локализовавшаяся на папиллярной мышце митрального клапана.

Больная Ж., 56 лет, поступила в НИССХ 12.01.2017 года с диагнозом новообразование левого желудочка. Предварительный диагноз (новообразование левого желудочка) был поставлен по месту жительства (Ки- ровоградская обл.) во время планового профилактического медицинского обследования. При проведении эхокардиографии в полости левого желудочка было выявлено подвижное новообразование небольших размеров, потребовавшее консультации кардиохирургов, в результате чего пациентка была направлена в НИССХ для дальнейшей диагностики и определения лечения. На момент поступления больная предъявляла жалобы на незначительную одышку, возникающую при физической нагрузке, а также периодические приступы сердцебиения и боли в области сердца, возникшие в последние несколько месяцев. Жалоб со стороны остальных органов и систем больная не отмечала.

В НИССХ больной был выполнен весь спектр диагностических процедур.

На ЭКГ - синусовый ритм с частотой 52 удара в минуту, признаки умеренной гипертрофии ЛЖ, что, скорее всего, явилось следствием повышения артериального давления.

По данным трансторакальной ЭхоКГ - в полости левого желудочка лоцировалось подвижное образование с нечеткими фрагментированными контурами, без капсулы, исходящее из папиллярных мышц, размерами 1,6х0,8 см, предположительно папиллярная фиброэластома (рис. 1 и 2) Значительная фрагментированность образования и высокая подвижность визуализируемых фрагментов предполагала высокую угрозу их отрыва с последующими эмболическими осложнениями. При этом гемодинамика не страдала. Левое предсердие было увеличено незначительно - до 4,2 см. Сократимость и размеры левого желудочка были в пределах нормы. Функция митрального клапана не нарушена.

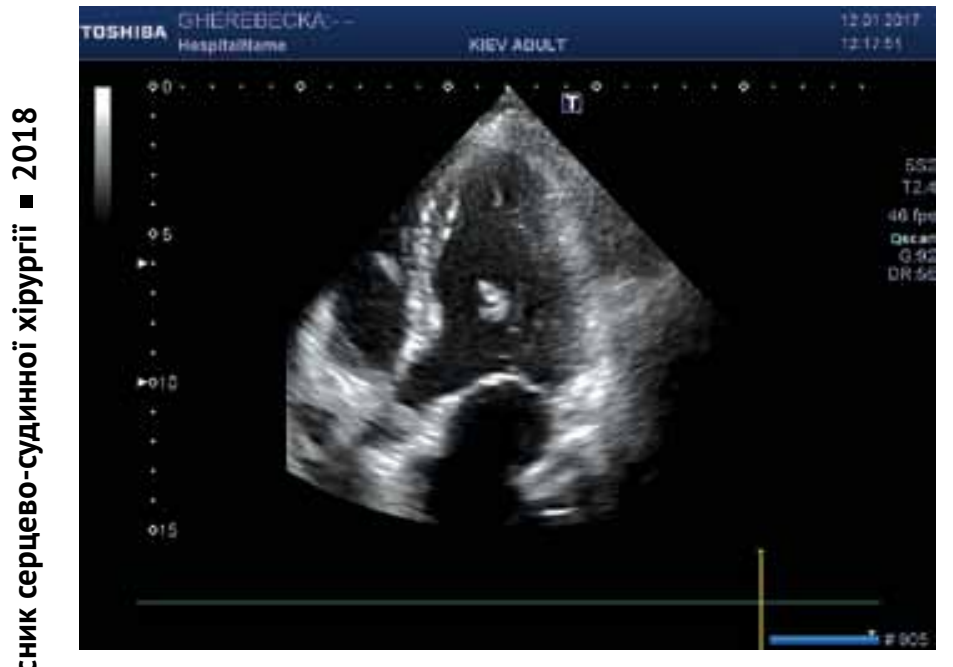

Рис. 1. Данные эхокардиографии. Новообразование в полости левого желудочка с фрагментированными краями

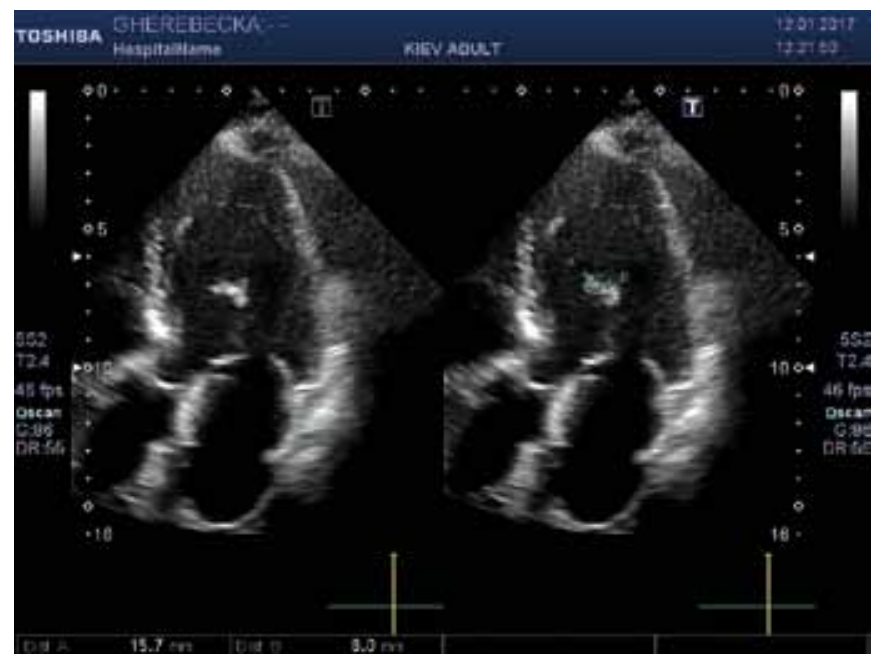

Рис. 2. По данным эхокардиогорафии размеры новообразования составляют $1,6 \times 0,8 \mathrm{~cm}$ 


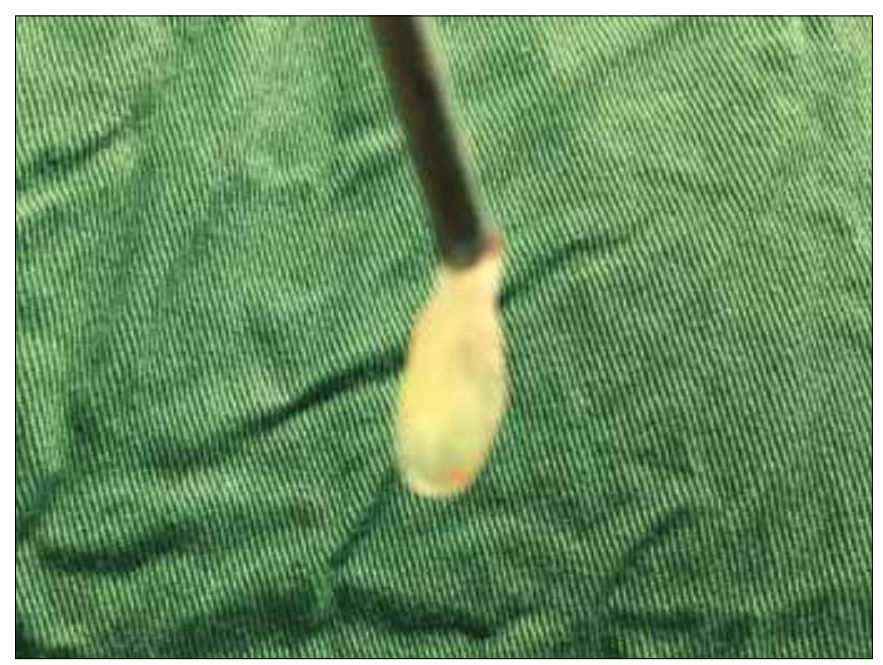

Рис 3. Новообразование левого желудочка. Пинцет фиксирует основание опухоли. Опухолевая ткань окружена физраствором

Коронарография показала отсутствие поражений в коронарных артериях.

Учитывая высокий риск эмболических осложнений, в связи с высокой подвижностью и фрагментированностью образования, несмотря на небольшие его размеры, было принято решение выполнить операцию по удалению новообразования в экстренном порядке.

13.01.2017 г. в условиях искусственного кровообращения, умеренной гипотермии и холодовой фармакологической кардиоплегии больной было выполнено хирургическое лечение - удаление опухоли (хирург Р. М. Витовский). При осмотре сердца выявлено умеренное увеличение сердца за счет левого предсердия и ПЖ. Удаление опухоли выполнялось доступом через правое предсердие и межпредсердную перегородку. Ревизия полости левого желудочка проводилась через отверстие митрального клапана, путем отведения его передней створки разогнутым крючком. Опухоль представляла собой образование мягкоэластической консистенции, гроздьевидной формы, размерами $1,7 \times 0,7 \times 0,8$ см (рис. 3).

Опухоль исходила из заднемедиальной папиллярной мышцы и прикреплялась короткой ножкой диаметром до 0,8 см к верхушке папиллярной мышцы, рядом с местом прикрепления хорд митрального клапана. Захватив пинцетом тело опухоли и несколько оттянув его от створки, новообразование скальпелем отсекли от папиллярной мышцы в пределах видимых здоровых мышечных тканей с последующей обработкой опухолевого ложа диатермией и прошиванием проленовым швом № 6. Удаленное новообразование представлено на рис. 3.

Ввиду близкого расположения места прикрепления новообразования непосредственно к хордам митраль-

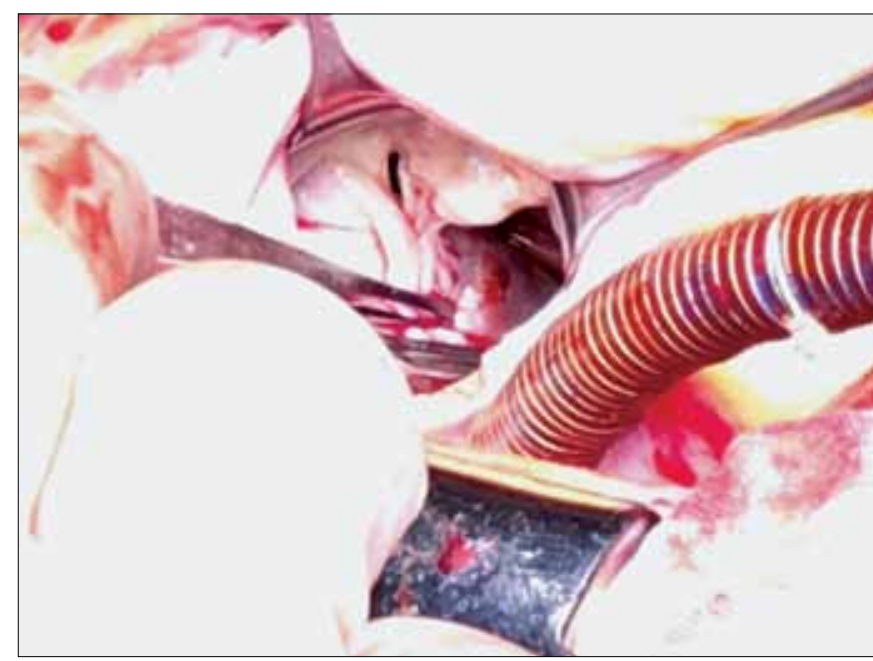

Рис. 4. Место прикрепления папиллярной фиброэластомы на папиллярной мышце митрального клапана после ее удаления

ного клапана была проведена гидравлическая проба на его компетентность, которая показала хорошую замыкательную функцию клапана. После герметизации камер сердца восстановлена сердечная деятельность. Время пережатия аорты составило 35 мин., искусственного кровообращения - 51 мин.

Истинная макроструктура новообразования, представляющая собой выраженную ветвистость с множественными мелкими и крупными отростками, напоминающими ветви дерева, была рассмотрена после помешения его в чашку Петри с физраствором (рис. 5).

Проведенное патогистологическое исследование подтвердило предполагаемый характер новообразования, которое оказалось папиллярной фиброэластомой.

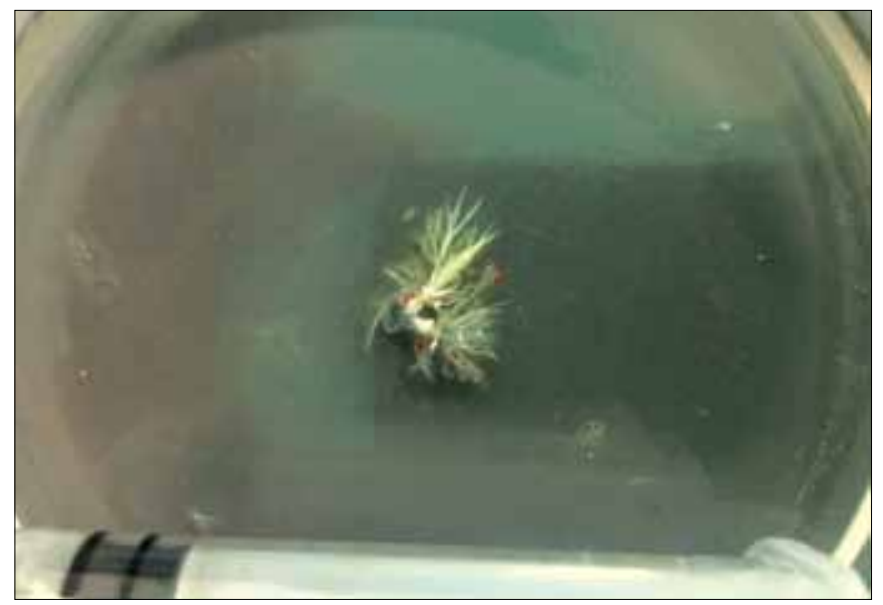

Рис. 5. Макроструктура удаленной папиллярной фиброэластомы, помещенной в физиологический раствор 
Послеоперационный период протекал без осложнений. Контрольная трансторакальная ЭхоКГ выявила отсутствие признаков опухоли. Признаков митральной недостаточности не было. Пациентка была переведена на самостоятельное дыхание через 4 часа после окончания операции. В общеклиническое отделение переведена на 2-е сутки. В удовлетворительном состоянии больная была выписана на 10-е сутки после операции и направлена для дальнейшего наблюдения кардиологом по месту жительства.

Обсуждение. Папиллярная фиброэластома (фиброэластическая папиллома, папиллома клапанов, фиброма клапанов) - доброкачественное внутриполостное образование, исходящее из эндокарда [2, 5, 7]. ПФ может поражать любой отдел сердца, но наиболее часто - хордальный аппарат и створки клапанов [5-8]. В $10 \%$ случаев отмечается множественный характер поражения. В абсолютном большинстве случаев поражаются левые отделы сердца $[10,11]$.

Макроскопически ПФ представляет собой, как правило, небольшую опухоль диаметром 1,5-2,0 см белесоватого цвета, мягко- или плотноэластической консистенции, напоминающую сосочковые разрастания эндокарда Lambl's. Однако имеются сообщения о более крупных вариантах опухоли [11].

Диагностика ПФ чрезвычайно трудна, т. к. патогномоничных клинических и лабораторных признаков она не имеет $[6,12]$. Возникающий стеноз или недостаточность клапана может быть следствием поражения клапана опухолевым процессом [2, 4, 12]. Клиническая симптоматика, зависящая от размеров и локализации опухоли, ограничивается чаще аускультативными особенностями, связанными с характером поражения клапанов, реже - с застойной сердечной недостаточностью $[6,11]$. О возможности наличия этой опухоли необходимо помнить в тех случаях, когда подозревается инфекционный эндокардит и при эхокардиографии выявляются вегетации на клапанах сердца [6].

Применение ЭхоКГ обеспечило точную и своевременную диагностику опухолей сердца. Этот метод стал основным в комплексе диагностических мероприятий при ПОС, разрешающая способность которого в настоящее время приближается к 100\%. В частности, двухмерное сканирование предоставляет возможность регистрировать в реальном масштабе времени размеры и форму новообразований, место их прикрепления, подвижность, соотношение с клапанным аппаратом, степень нарушения гемодинамики. Это позволяет уже в поликлинических условиях поставить правильный диагноз и выработать оптимальную хирургическую тактику лечения. Этому способствуют многоплоскостные, а при небольших опухолях - повторные многократные эхокардиогра- фические исследования. Немаловажную роль в точной диагностике ПФ играет чреспищеводная эхокардиография [6, 12].

Естественный прогноз при ПФ может быть различным. Локализуясь на клапанном аппарате, ПФ может нарушать его функцию, вызывая сужение просвета клапана или его недостаточность [5, 8, 9]. Кроме того, значительная подвижность внутрисердечной опухоли создает условия для высокой вероятности фрагментации опухоли с последующей эмболией артериальных сосудов, о чем свидетельствуют наблюдения, в которых она служит непосредственной причиной клапанной дисфункции, эмболического синдрома или внезапной смерти [9]. В преобладающем же большинстве случаев ПФ развивается бессимптомно и обнаруживается случайно - при вскрытии или кардиохирургических вмешательствах [6, 7].

Учитывая высокую вероятность эмболических осложнений, показания к проведению оперативного лечения возникают сразу после выявления опухолевого поражения клапана, несмотря на бессимптомность течения заболевания [2, 6, 7]. Большой арсенал пластических операций позволяет во многих случаях клапанного поражения опухолью удалить новообразование с сохранением функции клапана $[8,9]$. При этом рецидивирование удаленной ПФ отмечается крайне редко [7].

Выводы. Папиллярная фиброэластома - редкое опухолевое заболевание сердца с преимущественным поражением его хордально-клапанного аппарата. Однако наблюдаются и другие локализации новообразования, с поражением эндокардиальной поверхности сердца. Течение заболевания часто бывает бессимптомным при отсутствии поражения клапанных структур. Выявление подвижного новообразования фрагментированной структуры внутрисердечной локализации вызывает необходимость экстренного оперативного вмешательства, направленного на удаление опухоли.

Описанный случай демонстрирует возможность внеклапанной локализации и бессимптомного течения папиллярной фиброэластомы. При этом тактика экстренного и радикального хирургического лечения всегда должна быть соблюдена.

\section{Литература}

1. Кнышов Г. В., Витовский Р. М., Захарова В. П. Опухоли сердца. - К., 2005. - 256 с.

2. Особенности диагностики и хирургического лечения первичных доброкачественных опухолей сердца / Витовский Р. М., Пищурин А. А., Исаенко В. В. и др. // Вісник серцево-судинної хірургії. - 2017. - № 2. Вип. 28. - С. 33-35.

3. Cardiac tumors: classification and epidemiology. In Cardiac Tumor Pathology / Thiene, G., Basso, C., Rizzo, S. et al. - Humana Press, 2013. - P. 23-30. 
4. Burke, A., \& Tavora, F. (2015). The 2015 WHO Classification of Tumors of the Heart and Pericardium. Journal of Thoracic Oncology.

5. Experience of Cardiac Papillary Fibroelastoma Surgical Treatment / L. Brendel , K. Buschmann , L. Marzban et al. // Thorac cardiovasc Surg. - 2016. - Vol. 64. ePP119.

6. Cardiac Papillary Fibroelastoma is a Rare Cardiac Tumor with Large Variety of Symptoms: A Retrospective SingleCenter Study / K. Ort, K. Holke, N. Teucher et al. // Thorac cardiovasc Surg. - 2016. - Vol. 64. - ePP117.

7. Fleischmann, K. E., \& Schiller, N. B. Papillary Fibroelastoma: Move Over Myxoma // Journal of the American College of Cardiology. - 2015. - Vol. 65 (22). P. 2430-2432.

8. Papillary fibroelastoma of the aortic valve: analysis of 21 cases, including a presentation with cardiac arrest /
Ikegami H., Andrei A. C., Li Z. et al. // Texas Heart Institute Journal. - 2015. - Vol. 42 (2). - P. 131-135.

9. Cardiac Papillary Fibroelastoma: Single-Institution Experience with 14 Surgical Patients / Abu Saleh W. K., Al Jabbari O., Ramlawi B. \& Reardon M. J. // Texas Heart Institute Journa. - 2016. - Vol. 43(2). - P. 148-151.

10. Vallurupalli S., Hayes K., Bhatti S. Ventricular papillary fibroelastoma // Journal of the American College of Cardiology. - 2016. - Vol. 63 (20). - P. 2170-2170.

11. Falk-Udo Sack Fibroelastoma Recurrence in Left Ventricle: Rarity of Primary Cardiac Tumor / Inna Kammerer, Reinhard Besser, Mohammed Al-Azani et al. // Surg J. 2015. - Vol. 01 (01). - P. e35-e37.

12. Muretti, M., Massi, F., \& Portoghese, M. (2015). Diagnostic images of cardiac papillary fibroelastoma and video-assisted surgery. Asian Cardiovascular and Thoracic Annals, 0218492315583416.

\title{
Papillary fibroelastoma of unusual localization, a case from practice
}

\author{
R. Vitovskiy, V. Zakharova, D. Dyadyun, V. Isaenko, P. Semeniv \\ ${ }^{1}$ National M. M. Amosov Institute of Cardiovascular Surgery National Academy of Medical Sciences of Ukraine (Kyiv) \\ ${ }^{2}$ Shupyk National Medical Academy of Postgraduate Education (Kyiv)
}

Papillary fibroelastoma (fibroelastic papilloma, papilloma of valves, valve fibroma) is a benign intracavitary formation originating from the endocardium. PF can affect any department of the heart, but most often - the chordal apparatus and valve flaps. In $10 \%$ of cases, the multiple nature of the lesion is noted. In most cases, the left heart is affected. Macrophysically, the PF is usually a small tumor with a diameter of $1.5-2.0 \mathrm{~cm}$, whitish in color, of a soft or dense elastic consistency, reminiscent of papillary growth of the endocardium of Lambl's. Diagnostics of the PF is extremely difficult, because it hasn't pathognomonic clinical and laboratory features. The use of echocardiography provided accurate and timely diagnosis of the tumor.

The purpose of this work was to demonstrate the features of localization, clinical course and surgical treatment of papillary fibroelastoma of the left ventricle.

Materials and methods. As of 01/01/2018, in the NICVS N.M. Amosova, 916 patients with heart tumors were treated. Papillary fibroelastoma was diagnosed in 9 cases, which was $1.0 \%$ among all primary heart tumors.

Results and discussion. We present the results of the clinical observation of another patient who had a papillary fibroelastoma, localized on the papillary muscle of the mitral valve. According to transthoracic Echo KG, a mobile formation with fuzzy fragmented contours, without a capsule, originating from papillary muscles, $1.6 \mathrm{x} 0.8 \mathrm{~cm}$ in size, was found in the cavity of the left ventricle. A significant fragmentation of the formation and high mobility of the visualized fragments suggested a high threat of their detachment from subsequent embolic complications. Due to high mobility and fragmentation of formation, it was decided to perform an operation aimed at removing the tumor, in an emergency.

Conclusions. The described case demonstrates the possibility of non-valvular localization and asymptomatic flow of papillary fibroelastoma. In this case, the tactics of emergency and radical surgical treatment should always be observed.

Key words: heart tumors, papillary fibroelastoma, transthoracic echocardiogram, surgical treatment

\section{Папілярна фіброеластома незвичної локалізації (випадок із практики) \\ Вітовський Р. М. ${ }^{1,2}$, Захарова В. П. ${ }^{2}$, Дядюн Д. М. ${ }^{2}$, Исаєнко В. В. ${ }^{1}$, Семенів П. М. ${ }^{2}$ \\ ${ }^{1}$ ДУ «Національний інститут серцево-судинної хірургії імені М. М. Амосова НАМН» (Київ) \\ ${ }^{2}$ Національна медична академія післядипломної освіти імені П. Л. Шупика (Київ)}

Папілярна фіброеластома (фіброеластична папілома, папілома клапанів, фіброма клапанів) - доброякісне внутрішньопорожнинне утворення, що виходить з ендокарда. Папілярна фіброеластома (ПФ) може вражати будь-який відділ серця, але найбільш часто - хордальний апарат і стулки клапанів. У $10 \%$ випадків відзначається множинний характер ураження. В абсолютній більшості випадків уражаються ліві відділи серця. Макроскопічно ПФ зазвичай являє собою невелику пухлину діаметром 1,5-2,0 см, білястого кольору, м'яко- або міцноеластичної консистенції, що нагадує сосочкові розростання ендокарда Lambl's. Діагностика ПФ надзвичайно важка, оскіль- 
ки патогномонічних клінічних і лабораторних ознак вона не має. Застосування ЕхоКГ, як правило, забезпечує точну та своєчасну діагностику пухлини.

Метою роботи $є$ демонстрація особливостей локалізації, клінічного перебігу та хірургічного лікування папілярної фіброеластоми лівого шлуночка.

Матеріали та методи. Станом на 01.01.2018 року в НІССХ імені М. М. Амосова НАМН проводилося лікування 916 хворих із пухлинами серця. Папілярна фіброеластома була діагностована в 9 випадках, що склало 1,0\% серед усіх первинних пухлин серця.

Результати та обговорення. Ми представляємо результати клінічного спостереження чергового пацієнта, у якого була виявлена папілярна фіброеластома, локалізована на папілярному м'язі мітрального клапана. За даними трансторакальної ЕхоКГ, в порожнині лівого шлуночка лоціювалося рухоме утворення з нечіткими фрагментованими контурами, без капсули, що виходило з папілярних м'язів, розмірами 1,6х0,8 см. Значна фрагментованість утворення і висока рухомість візуалізованих фрагментів передбачала високу загрозу їх відриву з подальшими емболічними ускладненнями. 3 огляду на це було прийнято рішення виконати операцію, спрямовану на видалення новоутворення, в екстреному порядку.

Висновки. Описаний випадок демонструє можливість позаклапанної локалізації та безсимптомного перебігу папілярної фіброеластоми. При цьому слід завжди дотримуватися тактики екстреного та радикального хірургічного лікування.

Ключові слова: пухлини серия, папілярна фіброеластома, трансторакальне ЕхоКГ, хірургічне лікування. 